\title{
Effectiveness of gaseous stimulation in low intensity latex harvesting in rubber plantations of Sri Lanka
}

\author{
V H L Rodrigo* and K V V S Kudaligama* \\ * Rubber Research Institute of Sri Lanka, Dartonfield, Agalawatta, Sri Lanka
}

Received 20 December 2012

\begin{abstract}
Prevailing high price for rubber attracts growers to practise ethylene based gaseous stimulated harvesting as a method of efficient utilization of high panels and obtaining high yields at the last stage of the rubber tree. With no previous records, the present study was aimed to assess the effectiveness of gaseous stimulated harvesting systems in large scale application under Sri Lankan conditions. This system was found to be financially viable in terms of increased overall profitability and benefit cost ratio. Agronomically, it was effective with reduced bark consumption lengthening the harvesting period and increased worker use efficiency. Harvesters' income increased with the application of the system motivating workers to be engaged in latex harvesting. In order to assure the full benefits, proper application and maintenance of the system and monitoring of tapping quality are essential. Potential reduction in the price of gas jacket and increase in tapping task size are also critical factors for the profitability of the system. Effect of the price of rubber and other commodities on the overall profitability is also discussed.
\end{abstract}

Key words: ethylene stimulation, financial profitability, G-Flex, Hevea, rubber tapping

\section{Introduction}

For convenience, the bark of the rubber tree is generally tapped downwards on base panels. Tapping on high panels is undertaken during the last stage of the rubber tree as a way of intensified harvesting for high yields. Intensification of harvesting can be done either by increasing the frequency of harvesting and/or increasing the 44 tapping cut length. The traditional way of half spiral tapping cut (S/2) with once in two days harvesting (d2) is considered to be the standard (i.e. 100\% intensity) and any increase tapping cut length and/or frequency increases the level of intensity. It is believed that such intensification provides latex more than what the tree can sustain hence has not been proven successful in long-term 
(Tupy, 1973; Abraham et al., 1976). At the verge of uprooting, no matter how much latex is taken out; however, latex harvesting in last six years is to be planned through a gradual increase in intensification from $150 \%$ at the beginning to $400 \%$ at the end (Nugawela, 2006). Whilst additional quarter spiral cut provides the intensification of $150 \%$, two and then four half spiral cuts offer $200 \%$ and $400 \%$ intensifications, respectively with same harvesting frequency.

In addition to the above mentioned mechanical intensification, chemical intensification for high yields could be undertaken with latex stimulants. Despite the different compounds used, ethylene is the ultimate stimulant which results in enhanced latex synthesis through the conversion of sucrose (Tupy, 1973), increased turgor pressure in latex vessels (Pakianathan, 1977) and extended period of latex flow after tapping (Gomez, 1983). Chemical, instead of mechanical, intensification saves the bark allowing prolonged usage. Being not tapped before (i.e. virgin bark), high panels have the capacity to provide high yields. Further, upward tapping in high panels is exposed to greater area of latex drainage, another cause for high yields (Nguyen et al., 1997). Therefore, usage of high panels is to be advocated carefully to obtain the maximum yields. In general, a time period of $c a$. 12 years is to be allowed for proper regeneration of the bark after tapping. High level of bark consumption associated with unskilled and/or intensified tapping, does not allow sufficient time for bark renewal in most instances resulting in low yields in renewed bark of base panels and reduced tapping cycle. Therefore in the instances where the bark of base panels has been consumed quickly and/or tapping cycle is to be extended further, upward tapping on high panels can carefully be undertaken before the mechanical intensifications mentioned before. In particular, reduced bark consumption with either less number of tapping days and/or shorter tapping cuts is practised here in view of saving the bark for the future e.g. Control Upward Tapping (CUT) (Rodrigo \& Kudaligama, 2009). Among the approaches in this line, two approaches are usually adopted, i.e. direct use of ethylene with a minute cut (i.e. gaseous stimulation with $\mathrm{S} / 8$ cut length) and the use of liquid based slow release compounds of ethylene (i.e. ethephon with S/4 cut length). Obviously, the former is having advantages of very low levels of bark consumption and high levels of responses (Sivakumaran, 1991); however it is rather expensive and difficult in field applications. The latter is quite simple though the bark consumption is comparatively higher than gaseous stimulated systems.

Ad hoc application of yield stimulants was found to be unsafe; however, its judicious application is quite useful in LIH systems to save the bark and labour use (Chandrasekera, 1973; Satchuthananthavale \& Weerasinghe, 1977; Rodrigo et al., 2011 \& 2012). Instead of Ethephon, direct use of ethylene is 
marketed as a method of efficient utilization in high panels and also to address the labour shortage in tapping. Puncture tapping was initially tried with ethylene [e.g. Hypodermic Latex Extraction (HLE)] but failing that, mini cuts were introduced. The Rubber Research Institute of Malaysia made some modifications to the ethylene based gaseous stimulation and introduced a system called 'RRIMFLOW' in 1990 (Said \& Ramlan, 2006). Another system called 'REACTORRIM' was also introduced with a smaller size jacket coupled with a buffer tank for ethylene gas (Anon, 2011). The RRIMFLOW technique was introduced to Sri Lanka in 2005 (Rodrigo, 2006). Considering the difficulties in fixing jacket, another gaseous stimulation system with sticker type jacket named as Patch n' Tap was also introduced. Although the jacket of Patch n' Tap was very easy to be fixed, it had two inherent problems - to witwater trapped in the jacket could not be removed and the gas penetration to the tree was weaker in some cases. Therefore, the system did not last long in Sri Lanka. Nevertheless, an improved version of this system, G-Flex has been introduced recently facilitating to remove the water trapped inside the jacket. Despite the recommendations made by the manufacturers to inject ethylene in every 12 days, studies in Sri Lanka on the RRIMFLOW and G-Flex have shown the ideal/sustainable gassing frequency as once a month
(Rodrigo \& Kudaligama, 2009). At the moment, these systems are said to be used in Malaysia and some other countries in old rubber fields (over 15 years old).

Despite the high cost in application, the prevailing high price of rubber attracts growers to practise gaseous stimulation as a method of efficient utilization of high panels and obtaining high yields at the last stage of the rubber tree. In Sri Lanka, there is no much experience in large scale application of this system. Any implication in technology adoption, growers'/workers' perception and financial viability are to be assessed. Therefore, the present study was aimed to assess such parameters in the gaseous stimulated commercial rubber fields in Sri Lanka.

\section{Material and Methods}

Among the two gaseous systems available in Sri Lanka, i.e. RRIMFLOW and G-Flex, the latter has effectively been promoted by A. Baur \& Co. (Pvt.) Ltd. Therefore, seven such estates (named from $A$ to $G$ ) which practised this system in large scale were selected for the study in 2011. Details of the estates taken for the study are given in Table 1. Assessments were on three directions, i.e. on-site data collection on the application technique including its impact on the yield parameters, financial evaluation at the estate level and interviews on grower/worker perception. 
Problems encountered such as lack of supervision, latex thieving, leaking jackets, etc., led to discontinue this system in four estates whilst one estate continued with poor performance (e.g. leaking jackets, latex thieving). Out of seven sites, only two estates (named as $\mathrm{A}$ and $\mathrm{B}$ ), continued successfully with 10,000 trees in each by the end of study. Only these estates were taken for yield assessments. In each tree, G-Flex jackets were fixed and rainguards applied to cover tapping panel from rain interference. Trees were tapped upward on upper virgin bark with $\mathrm{S} / 8$ spiral cut once in three days with monthly stimulation rounds using ethylene gas cylinders. Tapping was undertaken only for seven months in a year (i.e. yielding months from June/July to December/January). Tapping during the rest of the period was done on base panels with traditional half spiral cut once in two days. According to the international notation for latex harvesting technology (Vijayakumar et al., 2009), this system could be denoted as $\mathrm{S} / 2 \mathrm{~d} 25 \mathrm{~m}$ (Jan-Jul)/12; S/8U(RG) d3 $7 \mathrm{~m}$ (Jun/Jul-Dec/Jan)/12 ETG100\%18$7 / y(m)$. Details of these two estates are given in Table 1.

Daily latex yields in these estates were assessed as the daily intake per harvester (IPH) and numbers of trees tapped by a harvester (i.e. size of tapping task). With that, yield per tree per tapping was calculated in grams (GTT). Also, dry rubber content of latex (\%DRC) was recorded. Each estate had different size of tapping task (varying from 300 to 400) and tree density per hectare (from 325 to 385 ). Considering the general situation in the plantation sector, standards were set as 300 trees for a tapping task and 350 trees per hectare for ease comparison. On that basis, IPH was recalculated together with the latex yield per hectare per tapping. Subjected to site variation, an average of eight tapping days per tree per month was under taken during the seven months of harvesting. With this information, yield per tree (YPT) and yield per hectare (YPH) for the seven month period was estimated. Bark consumption rate, incidence of tapping panel dryness of trees and other bark abnormalities such as bark wounds and borer attacks were assessed at the end of the study. Also at this stage, the perceptions of growers and workers on the gaseous stimulation were also assessed using semi structured intervals. Yield performance under the $\mathrm{S} / 2 \mathrm{~d} 2$ harvesting system of each site was assessed against its average yield performance before the application of gaseous stimulation. Harvesting frequency had been once in two days with half spiral tapping cut on base panels. As for the gaseous stimulation, yield parameters were standardized for the seven month period for comparison. Because of $\mathrm{d} 2$ frequency, number of tapping days per tree per month was taken as 12 and other standards were similar to those for the gaseous system. 
Table 2. Details of cost components in gaseous stimulated harvesting

\begin{tabular}{lr}
\hline Cost component & Value (Rs.) \\
\hline Gas cylinder (Average 2500 shots) & $16,000.00$ \\
Jacket & 120.00 \\
Labour payment for panel marking in 200 trees & 572.00 \\
Labour payment for fixing jackets in 300 trees & 572.00 \\
Labour payment for gas stimulation in 300 trees & 380.00 \\
Total cost per rainguard (including labour for fixing) & 40.00 \\
Payment to harvesters on extra latex (for over kilos) & 25.00 \\
Payment to harvester for scrap (Rs./kg) & 20.00 \\
\hline
\end{tabular}

Information on cost and benefit components of G-Flex system in the above estates was used for the assessment of financial viability with present market prices for commodities (Table 2). As generally practised in estates, the analysis was basically on short-term basis, i.e. for a year, and in Sri Lankan rupees for local importance (conversion rate: US\$ $=$ Rs.130.00). Being merely a technology for harvesting, mainly the changes in the tapping cost were taken into consideration. It comprised the initial investment on G-Flex system together with its field application and maintenance and also, the payment made for latex brought above the norm (Rs.25.00 per $\mathrm{kg}$ above $7 \mathrm{~kg}$ norm). Overhead costs (i.e. general charges), costs on immature and mature area upkeep were considered to remain unchanged at the estate level hence per hectare with the application of G-Flex system. Cost on raw rubber manufacturing from latex was considered to be a constant per kilogram of rubber produced. These costs, together with the tapping cost provided the overall cost of production. Difference in the yield before and after application of the harvesting system was considered in the estimation of benefits. Financial assessment was based on apportions of cost components per kilogramme of rubber produced, net income (profit) per hectare and per kilogramme of rubber produced and the benefit:cost ratio. In addition to general financial analyses with present market prices, the sensitivity of the profitability was assessed considering the potential variations in material costs of gaseous stimulation, worker wage, rubber price and tapping task size.

\section{Results}

The increase in latex yield in terms of yield per tree per tapping (GTT) and the estimated intake per harvester (IPH) with gaseous stimulation has increased on average by $95 \%$ in the two fields tested over the $\mathrm{S} / 2 \mathrm{~d} 2$ system (Table 3 ). Whilst the $\mathrm{S} / 2 \mathrm{~d} 2$ system accounted 84 
tappings per tree, number of tappings per tree in the new system was 56 during the seven month period. With that, average overall yield obtained under gaseous system was $2.6 \mathrm{~kg}$ per tree and $888 \mathrm{~kg}$ per hectare showing $28 \%$ increase over the yields given by the $\mathrm{S} / 2$ d2 system (Table 3). The percentage dry rubber content in latex (\%DRC) under the gaseous system was comparable with what given by the $S / 2$ d2 system (Table 3 ).

Linear length of bark consumed for a seven month period under the gaseous system was $22 \mathrm{~cm}$ (Table 4). Although only S/8 spiral was expected to be cut with gaseous stimulation, it has gone beyond this level by $c a .1 .36 \mathrm{~cm}$ in one estate. Trees affected with tapping panel dryness under this system were limited to about $8 \%$ in one estate and it was not the case in the other. Bark abnormalities were reported mainly in the Estate B with clone RRIM 600 and recorded primarily as the bark cracks with latex oozing out and borer attacks to the stem through the wounds (Table 5). Few incidences of trees with bark wounds and borer attacks were also found in Estate A (Table 5). Though not in a greater extent, a tendency of declining yields was reported by the staff of both estates. Poor quality accessories to the gas cylinder and lesser number of gassing per cylinder than recommended by the manufacturer were also reported by different categories of estate staff. Harvesters of both A and B estates were in favour of gaseous stimulated system for the increase in their income.
According to the supervisory staff, daily attendance of harvesters has been improved (Table 5). Reluctance of workers to attend late collection of latex resulted due to prolonged latex flow, thieving of latex and need for close supervision. These have led four estates (D to $\mathrm{G}$ ) to discontinue the gaseous stimulation. Even in estates that continued with, the same conditions were reported. In addition, estate $\mathrm{C}$ had leaking jackets too. Further, rolling nature of the terrain (steep slopes) has restricted the possibility of increasing the size of tapping task (i.e. number of trees allocated for a harvester per day) (Table 5).

Total cost involved in the application of gaseous stimulation was Rs.177.17 per tree and Rs.62,009.50 per hectare (Table 6). Out of total, 68\% was spent for the applicator whilst the cost on ethylene gas was only $10 \%$. The rest was for labour utilized in fixing the jackets and in monthly gassing. Because of applying gaseous stimulation, tapping cost has increased from Rs.83.14 to Rs.131.33 per kg of rubber produced. In extent wise, this was Rs.116,692.33 per hectare with $105 \%$ increase from the $\mathrm{S} / 2 \mathrm{~d} 2$ system. Also, the overall cost of production has increased from Rs.261.09 to Rs.277.13 per kg of rubber produced. Despite a decrease in Rs. 6.04 per kg, net income (profit) per hectare has shown $99 \%$ enrichment to the traditional system (i.e. $\mathrm{S} / 2 \mathrm{~d} 2$ ). In land area wise, the application of gaseous system is resulted in additional net revenue of Rs.111,069.00 per hectare to 
the estate. The benefit: cost ratio (BCR) has also improved by $17 \%$ (i.e. from 1.63 in the $\mathrm{S} / 2 \mathrm{~d} 2$ system to 1.91 in the gaseous harvesting system) (Table 6). With the gaseous stimulated system, the daily income of harvesters has increased in the range of $42 \%$ to $50 \%$ in different sites. On average, a harvester has received additional Rs. 255.00 per day over the Rs. 582.00 recorded in the traditional $\mathrm{S} / 2 \mathrm{~d} 2$ system (Table 6).

Table 3. Comparative yield performance of G Flex gaseous stimulation system against the traditional $S / 2$ d2 system

\begin{tabular}{lcccccc}
\hline Estate & $\begin{array}{c}\text { \%Dry } \\
\text { rubber } \\
\text { content }\end{array}$ & $\begin{array}{c}\text { Monthly } \\
\text { tapping } \\
\text { days }\end{array}$ & $\begin{array}{c}\text { Intake per } \\
\text { harvester } \\
(300 \text { trees }) \mathrm{kg}\end{array}$ & $\begin{array}{c}\text { Daily } \\
\text { latex } \\
\text { yield per } \\
\text { tree }(\mathrm{g})\end{array}$ & $\begin{array}{c}\text { Yield per } \\
\text { tree } \\
(7 \text { months }) \\
\mathrm{kg}\end{array}$ & $\begin{array}{c}\text { Yield per } \\
\text { hectare } \\
(7 \text { months }) \\
\mathrm{kg}\end{array}$ \\
\hline $\begin{array}{l}\text { Estate A } \\
\text { G Flex }\end{array}$ & $30-32$ & 8 & 14.5 & 48 & 2.7 & 947 \\
$\begin{array}{l}\text { Estate B } \\
\text { G Flex }\end{array}$ & $30-34$ & 8 & 12.7 & 42 & 2.4 & 830 \\
S/2 d2 & 32 & 12 & 7 & 23 & 2.0 & 686 \\
\hline
\end{tabular}

Table 4. Linear bark consumption and the tapping panel width in gaseous stimulated harvesting

\begin{tabular}{lccc}
\hline Estate & $\begin{array}{c}\text { Girth } \\
\mathrm{cm}\end{array}$ & $\begin{array}{c}\text { Bark consumption } \\
(7 \text { months }) \mathrm{cm}\end{array}$ & $\begin{array}{c} \pm \mathrm{S} / 8 \text { cut } \\
\mathrm{Cm}\end{array}$ \\
\hline $\mathrm{A}$ & 88.14 & 21.34 & 1.02 \\
$\mathrm{~B}$ & 73.67 & 22.42 & 1.36 \\
\hline
\end{tabular}

Table 5. Stakeholder perception on gaseous stimulated harvesting

\begin{tabular}{llll}
\hline Estate & & \multicolumn{1}{c}{ Perceptions } \\
\cline { 2 - 4 } & Management & Supervisory staff & Harvesters \\
\hline A & $\bullet$ Yield levels are & $\bullet$ About $8 \%$ TPD trees. & $\bullet$ Income \\
& acceptable & $\bullet$ Bark abnormalities and borer & increased \\
& $\bullet$ Declining yield & attack on few trees & $\bullet$ Declining yield \\
& levels from $1^{\text {st }}$ to & $\bullet$ Less number of gas shots per gas & levels \\
& $2^{\text {nd }}$ year & cylinder than what manufacturer & \\
& $\bullet$ Tapping task could & mentioned & \\
be increased & $\bullet$ Improvement in the attendance of & \\
& $\bullet$ Continue for next & harvesters & \\
& year & &
\end{tabular}


Gaseous stimulation in latex harvesting

\begin{tabular}{|c|c|c|c|}
\hline \multirow[t]{2}{*}{ Estate } & \multicolumn{3}{|c|}{ Perceptions } \\
\hline & Management & Supervisory staff & Harvesters \\
\hline $\mathrm{B}$ & $\begin{array}{l}\text { - Yield levels are } \\
\text { acceptable } \\
\text { - Declining yield } \\
\text { levels } \\
\text { - Continue for next } \\
\text { year }\end{array}$ & $\begin{array}{l}\text { - Poor quality accessories of gas } \\
\text { cylinder } \\
\text { - Declining yield levels } \\
\text { - Less number of gas shots per gas } \\
\text { cylinder than what manufacturer } \\
\text { mentioned } \\
\text { - Bark of RRIM } 600 \text { clone is } \\
\text { sensitivity to gassing with wounds } \\
\text { around jacket } \\
\text { - Improvement in the attendance of } \\
\text { harvesters }\end{array}$ & $\begin{array}{l}\text { - Income } \\
\text { increased } \\
\text { - Declining yield } \\
\text { levels }\end{array}$ \\
\hline $\mathrm{C}$ & \multicolumn{3}{|c|}{$\begin{array}{l}\text { Despite the continuation; } \\
\text { - Yield levels were not up to the acceptable levels } \\
\text { - Leaking jackets } \\
\text { - Poor attendance of workers for late collections } \\
\text { - Latex thieving problems } \\
\text { - Difficult to increase the tapping task due to poor terrain }\end{array}$} \\
\hline $\mathrm{D}, \mathrm{E}, \mathrm{F}, \mathrm{G}$ & $\begin{array}{l}\text { Discontinued due t } \\
\text { - Needs close super } \\
\text { - Poor attendance o } \\
\text { - Latex thieving pro } \\
\text { - Yield levels were }\end{array}$ & $\begin{array}{l}\text { on } \\
\text { orkers for late collections } \\
\text { ms } \\
\text { up to the acceptable levels }\end{array}$ & \\
\hline
\end{tabular}

Table 6. Summary of the financial analyses on gaseous stimulated harvesting

\begin{tabular}{lrrr}
\hline Item & S/2 d2 & G-Flex \\
\hline Intake per harvester (kg) & 7 & 13.6 \\
Harvester's income (Rs/day) & for chemicals & 582.00 & 837.00 \\
Cost of stimulation (Rs/kg) & 0.00 & 17.65 \\
& for labour & 0.00 & 2.99 \\
Cost of stimulation (Rs./tree) & 0.00 & 177.17 \\
Cost of stimulation (Rs./hectare) & 0.00 & $62,009.50$ \\
Tapping cost with stimulation & (Rs/kg) & 83.14 & 131.33 \\
Cost of production (Rs./kg) & 261.09 & 277.13 \\
Net income (Rs/kg) & 138.91 & 122.87 \\
Net income (Rs/hectare) & $112,439.12$ & $223,507.99$ \\
Benefit: Cost & 1.63 & 1.91 \\
\hline
\end{tabular}


Price of the jacket fixed to the rubber tree for stimulation has shown to be a highly sensitive factor for the overall profitability (Fig. 1). With Rs.10/= reduction in its price, the profit level increases by Rs. 3,500.00 per hectare. The maximum tolerable price of the jacket, i.e. the point when the profit of the $\mathrm{S} / 2 \mathrm{~d} 2$ and gaseous stimulated system is equal, appeared to be Rs.758.59. Overall profitability was not highly sensitive to the price of the ethylene gas cylinder (Fig. 2). The profitability declines only by Rs. 98.00 with Rs. 100.00 increase in the cylinder price. Any change in worker wages on harvesting activities also showed a marginal effect on the profitability. With Rs.100.00 increase in their daily wage, the decline in profits was limited to Rs.7000.00 per hectare in the gaseous stimulated system and that was $28 \%$ less than the rate for the traditional $\mathrm{S} / 2$ d2 system (Fig. 3). In contrast, the tapping task size appears to be a high impact factor for the profitability. If the task size under the gaseous stimulation increases by 50 trees, the increase in profitability would be Rs.45,250.00 (19\%) (Fig. 4). Obviously, the market price of rubber has been a key factor affecting the profitability of both $\mathrm{S} / 2 \mathrm{~d} 2$ and gaseous stimulated harvesting systems; however, the comparative effect on the latter system was recorded higher (Table 6). The rate of increase in the profitability with a unit increase in rubber price was $65 \%$ higher in the gaseous system than in the $\mathrm{S} / 2 \mathrm{~d} 2$ system. With the increase in the rubber price by Rs. 100.00 per $\mathrm{kg}$, the profitability of gaseous system increased by Rs.121,500.00 per hectare though it was only Rs. 73,500.00 per hectare in the $S / 2$ d2 system (Fig. 5).

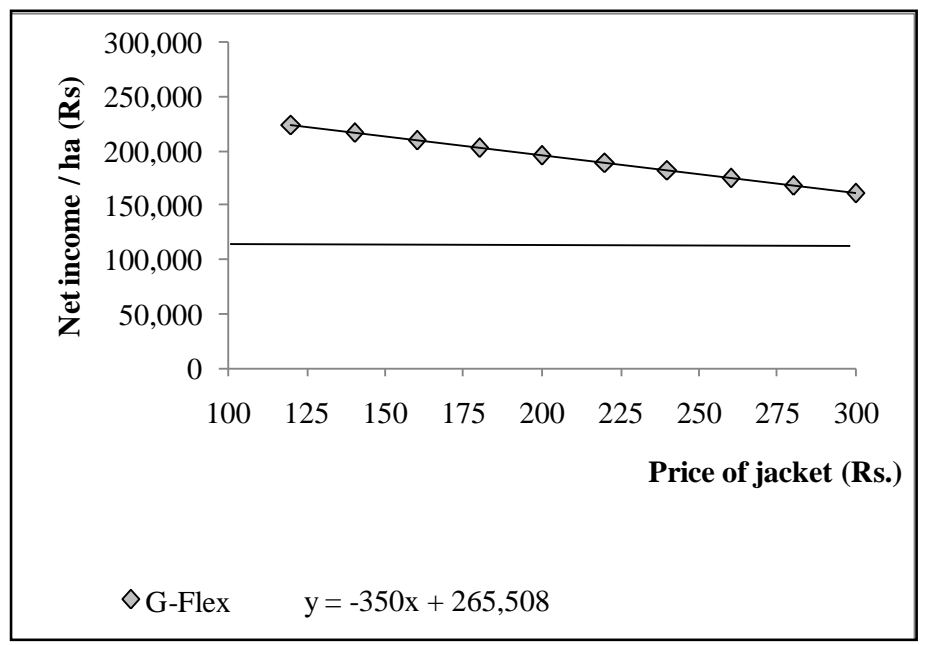

Fig. 1. Effect of the price of gas jacket on overall profitability in G-Flex harvesting. The profitability under the traditional $\mathrm{S} / 2 \mathrm{~d} 2$ harvesting is also shown for comparison 


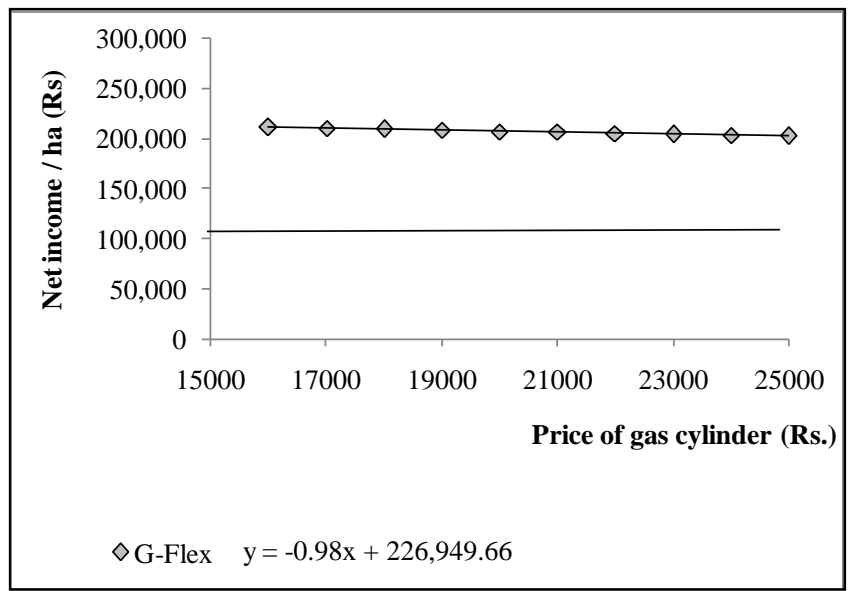

Fig. 2. Effect of the price of ethylene gas cylinder on overall profitability in G-Flex harvesting. The profitability under the traditional $\mathrm{S} / 2 \mathrm{~d} 2$ harvesting is also shown for comparison

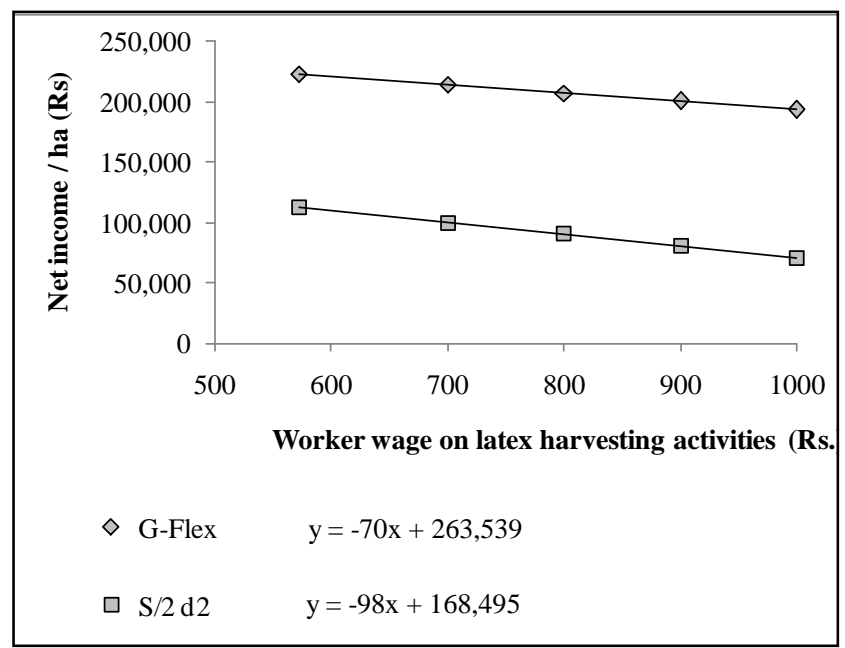

Fig. 3. Effect of worker wage for latex harvesting on overall profitability under both gaseous stimulated (G-Flex) and traditional S/2 d2 harvesting 


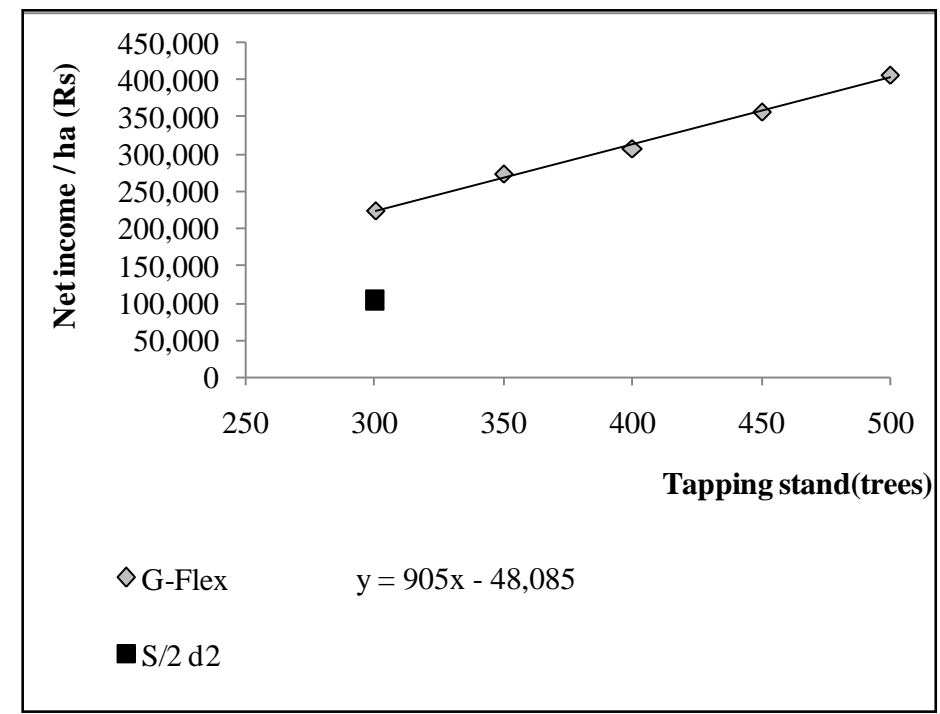

Fig. 4. Effect of tapping task size on the overall profitability in G-Flex harvesting. The profit of the traditional $\mathrm{S} / 2 \mathrm{~d} 2$ harvesting with 300 tree tapping task is also shown for comparison

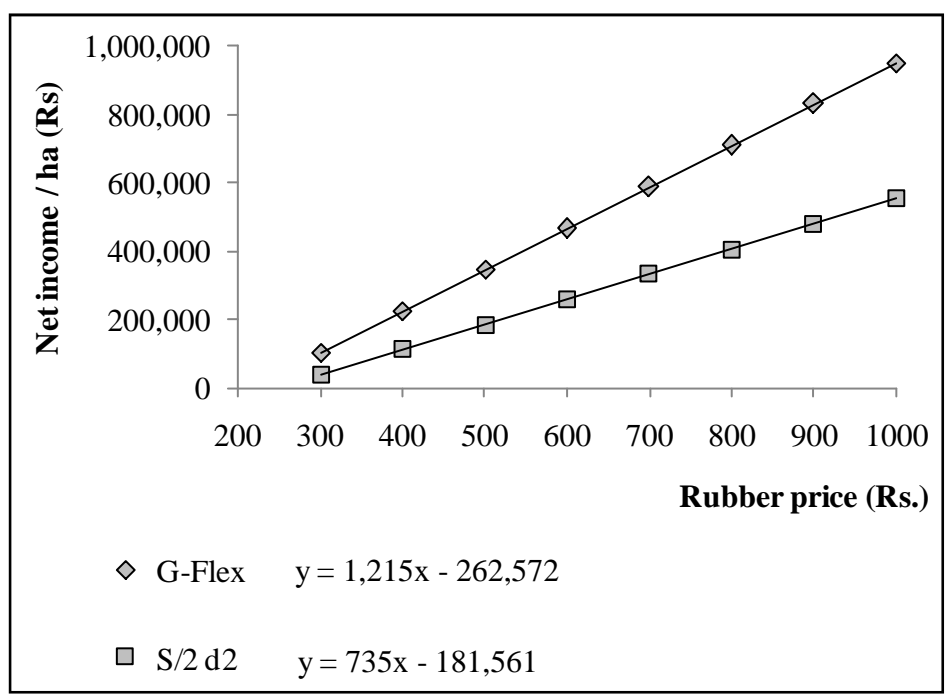

Fig. 5. Effect of rubber price on overall profitability under both gaseous stimulated (G-Flex) and traditional $\mathrm{S} / 2 \mathrm{~d} 2$ harvesting 


\section{Discussion}

According to results of this study, the gaseous stimulated harvesting system has given a higher profit per hectare over the traditional $\mathrm{S} / 2$ d2 system followed before. At present market price of rubber, this additional amount of profit was recorded as high as Rs.111,069/= per hectare which is sufficient enough to motivate rubber growers for this technology. In particular, higher BCR in the gaseous stimulated system shows higher rate of financial return for the investment. Any further increase in rubber price, the additional profits given by the gaseous system will increase further as the impact of rubber price is higher on the gaseous than on the $\mathrm{S} / 2 \mathrm{~d} 2$ system. At the price of Rs. 169.00 per $\mathrm{kg}$ of rubber, the profits of both systems are equal hence any drop in price below this level, the use of gaseous system would be of no financial advantage.

Despite the higher profit on land area basis, the profitability per $\mathrm{kg}$ of rubber produced declined with the application of the gaseous system. This is a result of the increase in cost of production (COP) associated with the new system, where extra Rs.48.00 is added to the COP per $\mathrm{kg}$ of rubber. Of this Rs.17.65 and Rs.2.99 per kg go for the chemicals and labour, respectively; the balance Rs.27.55 per kg accounts for the cost for gas jackets. This is further confirmed by the sensitivity analyses on material costs involved in gaseous stimulation where the variability of the profit was much higher with the change in the price of the jacket but less with the price of ethylene gas cylinder.

Ethylene is used in wide range of applications and so, its price would be rather competitive. Nevertheless, the jacket used in gaseous stimulation comprises with plastic/polythene components and a price reduction could be possible in large scale applications. If so, the profitability of the system will further increase with higher level of BCR. Technology adoption in any business depends not only on the overall profitability but also on the level of return for the investment as given by BCR. Any improvement in BCR in this technology would create a virtuous cycle where more rubber growers would practice the system enabling further reduction of cost and that in turn will attract more growers to practice new methods of application.

Although the standard size of tapping block (task size) is 300 trees, it has increased up to 400 trees in some sites. Gaseous stimulated system is also said to be applied in 500 tree tapping blocks in some other sites (Personal communication with A Baur \& Co. (Pvt.) Ltd). Despite the incentive payments made to harvesters for additional latex brought in over the norm and/or the provision of supplementary payment for latex collection, overall cost involved here is less than the value of extra latex obtained. Sensitivity analyses, has shown that the profitability increases at a rate of Rs.45,250.00 per 50 trees. Shorter tapping cut length in stimulated 
trees enables an increase in the task size; however it also depends on terrain type as walking from tree to tree takes more time than what is taken for just tapping (Silva, 2007). Increase in task size also results in another advantage, i.e. reduced requirement of harvesters. Nevertheless, this makes harvesters to carry more latex and therefore, it is essential to improve the facilities for latex transport.

The frequency of applying ethylene gas to rubber trees in this study was once a month as per the recommendation of the Rubber Research Institute of Sri Lanka (Rodrigo \& Kudaligama, 2009). Higher gassing frequencies have been recommended elsewhere for high yields (Sivakumaran, 1991). The suitability of the frequency applied in this study with Sri Lankan genotypes has been confirmed by no drop in the percentage of dry rubber content in latex (\%DRC) and the acceptable level in the incidence of Tapping Panel Dryness (TPD). However, some records of bark abnormalities were observed in this study particularly with the clone RRIM 600 . Unlike other clones used in this study, the RRIM 600 is known for its higher incidence of TPD, hence should carefully be studied when adopting low frequency harvesting systems with Ethephon stimulation (Gohet, et al., 2003). The once a month gassing frequency has been recommended for the clones usually tapped once in two days without stimulation (Rodrigo \& Kudaligama, 2009); hence the problems associated with RRIM 600 could be attributed to the higher level of ethylene stimulation. Therefore, the situation could be rectified by reducing the stimulation frequency and/or probably with reducing the frequency of tapping. As indicated in the present study, a time bound decline in yield was previously reported with gaseous stimulation system (Rodrigo and Kudaligama, 2009). This would have been associated with high level of stimulation converting more plant food reserves to latex at the beginning. However, it is expected to have stabilized yield levels with the acclimatization of the tree to stimulation.

The yield increase recorded here over the previously practised system (i.e. RRIMFLOW and Patch n' Tap) is mostly due to virgin bark tapped upwards. When compared to base panels tapped downwards, higher yields have been recorded in upward tapping (Nguyen et al., 1977; Vijayakumar et al., 2003) due to a greater drainage area for latex. Obviously, latex vessels in the virgin bark are not distorted hence capable of providing more latex. Therefore in upward tapping in high panels, the bark should carefully be utilized. Techniques to obtain the potential amount of latex what the tree can provides with lesser amount of bark consumed is important here for extended period of benefits. In addition to the effect on latex synthesis (d'Auzac, 1989), ethylene increases the drainage area of latex (Ribaillier \& d'Auzac, 1970) and delay the plugging after tapping the tree (Abraham et al., 
1971). Therefore, gaseous stimulation facilitates to obtain the potential yield of the tree with a small incision saving the bark for a prolong period of tapping. Although cost effective liquid based stimulants which ultimately release ethylene (e.g. Ethephon), are available in the market, they are not effective enough to get the expected amount of latex with such a small cut. Instead of $1 / 8$ spiral cut, $S / 4$ cut has to be made in upward tapping on high panels should Ethephon be used (Nguyen, et al., 1977). Hence with gaseous stimulation, the period of tapping in high virgin panels could be doubled. Assuming only one year for each panel, high panels of the tree could be tapped for 8 years with gaseous system whilst the Ethephon based system with S/4 cut enables only 4 years of tapping.

Demand for worker wage increases is inevitable and that could be met with no loss to the estates. LIH systems are effective here with increase in worker use efficiency. As observed in this study, harvesters were able to get up to $44 \%$ increase in their daily wages. Similarly, $28 \%$ increase daily wages has been reported with LIH in base panels in Sri Lanka (Rodrigo, et al., 2011). Estate workers are considered to be in one of poorest sectors in the country and regular wage increases are essential for them to meet the rising cost of living. In addition, it also prevents emigration of estate labour to other sectors. Increase in daily attendance of harvesters with the application of gaseous stimulation system is indicative of the interest of workers in latex harvesting using a new method.

Despite the bark saving due to $\mathrm{S} / 8$ tapping cut length in gaseous stimulation, linear rate of bark consumption recorded in this study is very high. It has been shown that 1.25 $\mathrm{mm}$ shaving thickness is sufficient in latex harvesting (Nugawela, 2001). With that, annual rate of linear bark consumption with once in three days tapping should be $c a .14 \mathrm{~cm}$. However in practice, there is a tendency to have a higher rate of bark consumption in upward tapping on high panels and so, 20-25 cm of bark consumption is generally allowed. Bark consumption rate recorded in this study was $213 \%$ higher than the recommended level thereby threatening the long-term benefits of the gaseous stimulation. Extension of the tapping cut above the $1 / 8$ spiral has also been recorded. This would be an eye opener for rubber growers to take effective measures to maintain the tapping quality in whatever panel for the sustainability of the plantations. If not, expected benefits could not be obtained and also, it will lead to unconventional way of tapping (e.g. additional tappings) without the knowledge of top management.

In addition to the cost cutting in gas jackets, the quality of accessories has to be improved for the satisfaction of end user. Also, underpinning factors for the difference between practically feasible number of gassing shots per cylinder and what the manufacturer mentioned are to be looked into. Perhaps, there 
could be extra gassing going to the jacket and that would have resulted in bark abnormalities in some occasions. In gaseous stimulated latex harvesting, extra care should be taken for proper application and maintenance of the system. Also, no room for thieving of latex should be left and so, management factor appears to be very critical for the success of the system.

\section{Conclusions}

Gaseous stimulation was found to be effective in utilizing high panels of rubber trees. Period of harvesting extends with reduced bark consumption and overall profits increases by twofold at present market prices of commodities. Added cost in gaseous stimulation has resulted in an increase in $\mathrm{COP}$ (per $\mathrm{kg}$ of rubber produced); however, rate of return for the investment increased by $17 \%$ as indicated by BCR.

Requirement of harvesters can greatly be reduced in gaseous stimulation due to the increased allocation of trees to each harvester (in terms of greater number of tapping blocks per harvester and increased number of trees per tapping block). Instead of two tapping blocks each having 300 trees in the traditional $\mathrm{S} / 2 \mathrm{~d} 2$ system, each harvester could be given three blocks each with 400 trees in gaseous stimulation. Overall profitability of this system has shown to increase at a rate of Rs. $45,250 /=$ per every 50 tree increase in the tapping task.
Among the cost cutting factors, the price of jacket was found to be important. Just with Rs.10/= reduction in the price of jacket, the overall profit per hectare per annum could be increased by Rs.3500/=. Large scale adoption may facilitate for a price reduction of the jacket and increased profitability which will in-turn result in a virtuous cycle attracting more rubber growers for gaseous stimulated harvesting systems. Nevertheless, growers expect to have some quality improvements in the accessories of gas cylinder and this has to be taken into consideration in the improvement of the G-Flex system.

With increase in worker productivity (i.e. higher levels of intake per harvester), gaseous stimulated systems could be used to increase the wages of harvesters. In the present study, ca. 44\% increase in their wages was reported and that would further increase with the increase in the tapping task size. Therefore, this system would undoubtedly attract the workers to the latex harvesting profession.

The present study has shown higher level of bark consumption than what was anticipated. Also, leaking gas jackets, improper application of gassing and potential for thieving latex were evident. Therefore, proper management plan assuring tapping quality and correct application of the system is essential to obtain full benefits of gaseous stimulated harvesting. 


\section{Acknowledgement}

Ms. A. Baurs Company Limited is acknowledged for supplying gaseous systems to the experimental fields. Support given by the Management and their staff of respective estates to collect information is highly appreciated.

\section{References}

Abraham, P D, Blencowe, J W, Chua, S E, Gomez, J B, Moir, G F J, Pakianathan, S W, Sekhar, B C, Southorn, W A and Wycherley, P R (1971). Noval stimulants and procedures in the exploitation of Hevea. I. Introductory review. Journal of Rubber Research Institute of Malaya 23, 85-89.

Abraham, P D, P'Ng, T C, Lee, C K, Sivakumaran, S, Manikam, B and Yeoh C P (1976). Etheral stimulation of Hevea. In: Proceedings of the International Rubber Conference, Kuala Lumpur, 1975, II, Rubber Research Institute of Malaysia. pp347.

Anon (2011). REACTORRIM latex stimulant http://reactorrim.blogspot.com/ 2011/01/latest-modified-latex-stimulant. html (accessed on 18.12.2012)

Chandrasekera, L B (1973). A critical evaluation of the currently available results of some ethrel trials in Sri Lanka. Quarterly Journal of the Rubber Research Institute of Sri Lanka. 50, 1218.

d' Auzac, J (1989). The hormonal stimulation of latex yield. In: Physiology of Rubber Tree Latex 289-342 (Eds. J. d'Auzac, J. L. Jacob and H. Chrestin), CRC Press, Florida.

Gohet, E, Chanthuma, P, Lacote, L, Obouayeba, S, Dian, K, ClementDemange, A, Dadang Kurnia and Eschbach, J M (2003). Latex clonal typology of Hevea brasiliensis: Physiological modelling of yield potential and clonal response to Ethephon stimulation. Proceedings of the IRRDB Workshop on Exploitation Technology, Kottayam, India. Pp.199217.

Gomez, J B (1983). Physiology of latex (rubber) production, Rubber Research and Development Board of Malaysia, Monograph No 8.

Nguyen Anh Nghia, Mohd Fauzi Ramlan, Ghandimathi H, Yeang H Y and Mihdzar Abdul Kadir (1997). Effect of ethephon concentration on yield and some physiological parameters of Hevea brasiliensis latex from controlled upward tapping on clone RRIM 600. Proceedings of the IRRDB Symposium (Volume 2): Physiology and Exploitation and Crop Protection of Planting Methods, Ho chi Minh City Vietnam.

Nugawela, A (2001). Exploitation for economic yields, In: Hand Book of Rubber, Agronomy, 176-190 (Eds. L.M.K. Tillekeratne and A. Nugawela), Rubber Research Institute of Sri Lanka, Agalawatta, Sri Lanka.

Nugawela, A (2006). Stimulation of rubber trees for enhancing performance - The past, current practices and future trends. Bulletin of the Rubber Research Institute of Sri Lanka 47, 75-79.

Pakianathan, S W (1977). Some factors affecting yield response to stimulation with 2-chloroethylphosphonic acid. Journal of Rubber Research Institute of Malaysia 25, 50.

Ribaillier, D and d'Auzac J (1970). Nouvelles perspectives de stimulation hormonale de la production chez l'Hevea brasiliensis. Revue Générale $d u$ Caoutchouc et des Plastiques. 47, 433. 
Rodrigo, V H L (2006). Annual Review of Department of Biochemistry \& Physiology Department, Rubber Research Institute of Sri Lanka, pp.6977.

Rodrigo, V H L and Kudaligama, K V V S (2009). Gaseous stimulation for exploitation in rubber cultivation of Sri Lanka: An overview. The Journal of Plastic \& Rubber Institute of Sri Lanka 9, 23-35.

Rodrigo, V H L, Kudaligama, K V V S, Fernando, K M E P and Yapa, P A J (2011). Harvesting the rubber tree once in four days; a solution to current issues in the rubber industry in Sri Lanka. Journal of Rubber Research Institute of Sri Lanka 91, 15-35.

Rodrigo, V H L, Kudaligama, K V V S, Fernando, K M E P and Yapa, P A J (2012). Replacing the traditional half spiral cut by a quarter cut with Ethephon in latex harvesting; a simple approach to solve the current issues in the rubber industry. Journal of National Science Foundation 40(4), 283-291.

Said, M A M and Ramlan, M F (2006). Relationship between methods of latex extraction and stimulation on yield of RRIM 901, Panel BO-1. Journal of Rubber Research 9(4), 238-250.

Satchuthananthavale, $\mathrm{R}$ and Weerasinghe, $\mathrm{T}$ C (1977). Ethral stimulation of Hevea under conditions in Sri Lanka. Journal of Rubber Research Institute of Sri Lanka 54, 150-162.

Silva, T U K (2007). Effects of planting density on growth and yield of three different clones of rubber. MPhil Thesis, University of Sri Jayawardhenapura, Nugegoda, Sri Lanka.

Sivakumaran, S (1991). RRIMFLOW: A novel technique of exploitation of Hevea trees. Proceedings of the Rubber Growers Conference, Kuala Lumpur, 1991.

Tupy, J (1973). The level and distribution pattern of latex sucrose along the trunk of Hevea brasiliensis, as affected the sink region induced by latex tapping, Physiologie Vegetale, 11, 1.

Vijayakumar, K R, Gohet, E, Thomas, K U, Xiaodi, W, Sumarmadji, Rodrigo, L, Thanh, D K, Sopchoke, P, Karunaichamy, K and Said, M A M (2009). Revised international notation for latex harvesting technology. Published by International Rubber Research and Development Board.

Vijayakumar, K R, Thomas, K U, Rajagopal, $\mathrm{R}$ and Karunaichamy, $\mathrm{K}$ (2003). Extension of low frequency tapping and controlled upward tapping by researchers. Proceedings of the IRRDB Workshop on Exploitation Technology, Kottayam, India. Pp.267279.

Address for correspondence: Dr V H L Rodrigo, Head, Biochemistry and Physiology Dept., Rubber Research Institute of Sri Lanka, Dartonfield, Agalawatta, Sri Lanka.

e-mail:laksh@sltnet.lk 